\title{
An Investigation of Proton Conductivity of Vinyltriazole-Grafted PVDF Proton Exchange Membranes Prepared via Photoinduced Grafting
}

\author{
Sinan Sezgin, ${ }^{1}$ Deniz Sinirlioglu, ${ }^{1}$ Ali Ekrem Muftuoglu, ${ }^{2}$ and Ayhan Bozkurt ${ }^{1}$ \\ ${ }^{1}$ Department of Chemistry, Faculty of Arts and Science, Fatih University, Büyükçekmece, 34500 Istanbul, Turkey \\ ${ }^{2}$ Department of Chemical Engineering, Faculty of Chemical and Metallurgical Engineering, Yildiz Technical University, \\ Davutpaşa Campus, Esenler, 34220 Istanbul, Turkey
}

Correspondence should be addressed to Ali Ekrem Muftuoglu; ekremm@yildiz.edu.tr

Received 12 April 2014; Accepted 5 June 2014; Published 2 July 2014

Academic Editor: Barbara Gawdzik

Copyright (C) 2014 Sinan Sezgin et al. This is an open access article distributed under the Creative Commons Attribution License, which permits unrestricted use, distribution, and reproduction in any medium, provided the original work is properly cited.

\begin{abstract}
Proton exchange membrane fuel cells (PEMFCs) are considered to be a promising technology for clean and efficient power generation in the twenty-first century. In this study, high performance of poly(vinylidene fluoride) (PVDF) and proton conductivity of poly(1-vinyl-1,2,4-triazole) (PVTri) were combined in a graft copolymer, PVDF- -PVTri, by the polymerization of 1-vinyl1,2,4-triazole on a PVDF based matrix under UV light in one step. The polymers were doped with triflic acid (TA) at different stoichiometric ratios with respect to triazole units and the anhydrous polymer electrolyte membranes were prepared. All samples were characterized by FTIR and ${ }^{1} \mathrm{H}$-NMR spectroscopies. Their thermal properties were examined by thermogravimetric analysis (TGA) and differential scanning calorimetry (DSC). TGA demonstrated that the PVDF- $g$-PVTri and PVDF- $g$-PVTri-(TA)x membranes were thermally stable up to $390^{\circ} \mathrm{C}$ and $330^{\circ} \mathrm{C}$, respectively. NMR and energy dispersive X-ray spectroscopy (EDS) results demonstrated that PVDF- $g$-PVTri was successfully synthesized with a degree of grafting of $21 \%$. PVDF- $g$-PVTri-(TA) $)_{3}$ showed a maximum proton conductivity of $6 \times 10^{-3} \mathrm{Scm}^{-1}$ at $150^{\circ} \mathrm{C}$ and anhydrous conditions. CV study illustrated that electrochemical stability domain for PVDF-g-PVTri-(TA) ${ }_{3}$ extended over $4.0 \mathrm{~V}$.
\end{abstract}

\section{Introduction}

Quite recently, proton exchange membrane fuel cells (PEMFCs), also referred to as polymer electrolyte membrane fuel cells (PEMFCs), have garnered a great deal of attention which can be applied to a wide range of application areas such as water purification, gas separation, and fuel cells [1-10]. Proton exchange membranes (PEMs) are the key components in fuel cell systems and serve as an electrolyte for transporting protons from the anode to the cathode and as a separator to prevent mixing of the fuel gases $[1,3,4,10]$. Perfluorosulfonic acid (PFSA) membranes, the best known example of which, is DuPont Nafion, are most widely used as the electrolyte in fuel cell research. These membranes have high chemical stability and excellent mechanical properties and provide high proton conductivity in the fully hydrated state [3, 4, 8-10]. They form proton transfer channels due to the presence of both hydrophilic and hydrophobic regions. However, their high price, low stability at high temperatures, low conductivity at low humidity or high temperature, and high methanol permeability restrict the extent of their application and commercialization $[4,9,10]$. At high temperatures, the conductivity tends to decrease due to humidity loss. Therefore, the researchers have directed their efforts towards obtaining alternate membranes that are also stable and efficient at elevated temperatures [1-3, 6-9].

Engineering plastics have become the subject of many studies of developing proton exchange membranes used in fuel cells, which involve polytetrafluoroethylene (PTFE), pol$y$ (tetrafluoroethylene-co-hexafluoropropylene) (FEP), pol$y$ (tetrafluoroethylene-co-perfluoropropylvinylether) (PFA), poly(ethylene-alt-tetrafluoroethylene) (ETFE), poly(ether ether ketone) (PEEK), and poly (vinylidene fluoride) (PVDF) films. In these studies, the base film was modified via 
grafting using UV-light, $\gamma$-rays, electron beam, X-ray, and gamma radiation techniques [3, 9, 11-29]. Previously, Asano et al. reported on the development of proton-conducting membranes generated by the $\gamma$-ray radiation grafting of styrene and its derivatives onto fluorine-containing base films and subsequent sulfonation [12, 15, 22, 27]. However, due to the poor mechanical properties caused by high energy $\gamma$-ray preirradiation, use of these membranes in fuel cell applications would be limited [28]. To avoid degradation of the precursor polymer, the same research group used a novel UV-induced polymerization approach to graft styrene onto partially fluorinated poly(ethylene-cotetrafluoroethylene) (ETFE) and PTFE films. They obtained membranes with higher mechanical strength and similar proton conductivities compared with $\gamma$-ray radiation grafted ones and Nafion [16, 21].

Quite recently, we employed the above-mentioned UVinduced polymerization process in the grafting of styrene and 4-(chloromethyl)styrene onto partially fluorinated poly (vinylidene difluoride) (PVDF) $[3,9]$. It was seen that the degree of grafting increased with the grafting time, reaching above $100 \%$ after 8 hours while Asano and his coworkers reported about $10 \%$ increase in the degree of grafting of styrene on PTFE films after 8 hours [13]. Chen et al. also found that the degree of grafting for ETFE films reached up to 59\% after $6 \mathrm{~h}$ of UV irradiation [16]. The high grafting efficiency in our work was partly attributed to the fact that more initiating radicals might have formed on the surface of PVDF due to quantitative homolytic cleavage of $\mathrm{C}-\mathrm{H}$ bonds rather than sole $\mathrm{C}-\mathrm{F}$ bonds of PTFE $[3,9]$.

Azole functional membranes have received great interest in the fabrication of anhydrous PEMs, which are suitable for high temperature fuel cell applications [10]. In azole sidefunctional polymers, the aliphatic backbone chain improves the fabrication property, and the azole side groups may act as proton donors and acceptors. The proton transport occurs between hydrogen bonds of neighboring heterocyclic units through structure diffusion $[1,3,6,7,10]$. However, studies on grafted films containing readily available $\mathrm{N}$ heterocyclic monomers are very rare [23-25, 29]. Recently, Schmidt and Schmidt-Naake reported on the preparation of phosphoric acid (PA) doped 4-vinylpyridine (4VP) grafted poly(ethylene-co-tetrafluoroethylene), ETFE-graftpoly (4VP), by using radiation-induced grafting method [23]. Quite recently, Nasef et al. and Lepit et al. declared that the preparation of phosphoric acid (PA) doped 4-vinylpyridine (4VP) and 1-vinylimidazole (VIm) grafted ETFE and PVDF based electrolyte membranes were prepared via radiationinduced grafting method, respectively $[24,25,29]$. Therefore, it is remarkable that a graft copolymer consisting of 1-vinyl1,2,4-triazole (VTri) and a PVDF based matrix is prepared under UV light in one step to achieve an anhydrous PEMs.

In this contribution, PVDF- $g$-PVTri membranes were synthesized by UV-induced surface grafting of vinyl triazole (VTri) onto PVDF in a single step. They were subsequently doped with triflic acid to obtain anhydrous PEMs. All membranes were characterized by ${ }^{1} \mathrm{H}-\mathrm{NMR}$ and FTIR spectroscopic analysis. Their thermal properties were examined by thermogravimetric analysis (TGA) and differential scanning calorimetry (DSC) measurements. The surface morphology of the membranes was characterized by scanning electron microscopy (SEM). The proton conductivity of the membranes was investigated by dielectric-impedance analyzer for anhydrous PVDF- $g$-PVTri-(TA $)_{x}(x=1.0,2.0$ and 3.0) membranes.

\section{Experimental}

2.1. Materials. Polyvinylidene fluoride (PVDF, average $\mathrm{Mw}$ $\sim 534,000)$ was purchased from Fluka. Acetone $(\geq 99.9 \%)$ was purchased from Merck. Dimethylformamide (DMF, $\geq 99.9 \%$ ), benzophenone (BP, $\geq 99 \%$ ), polyvinyl acetate (PVA, average Mw 83,000), 1-vinyl-1,2,4-triazole ( $>97 \%)$, and trifluoromethanesulfonic acid were supplied from Aldrich. They were all reagent grade and used as received.

2.2. Preparation of $P V D F$ Membranes. The membranes were prepared from 7\% (w/w) PVDF polymer solutions in DMF according to our previous works $[3,9]$. The solution was cast on PTFE petri dish to obtain thin film and dried at room temperature for several hours before heating at $40^{\circ} \mathrm{C}$ for $2 \mathrm{~h}$ under vacuum. Finally, the polymer was recovered as a flatsheet membrane from the bottom of the PTFE petri dish. The thickness of the received membranes is in the range of 25-100 $\mu \mathrm{m}$. All PVDF films were cut into $2 \mathrm{~cm} \times 2 \mathrm{~cm}$ pieces and stored in vacuum at $40^{\circ} \mathrm{C}$ before use.

\subsection{Synthesis of Vinyltriazole-Grafted PVDF Membranes} (PVDF-g-PVTri). The UV surface photografting of VTri onto the PVDF base film was performed as follows. First, a $50 \mu \mathrm{m}$ thick PVDF film was immersed in acetone solution containing $0.5 \mathrm{wt} \%$ benzophenone, and $0.5 \mathrm{wt} \%$ poly(vinyl acetate) (PVA) for 5-8 s at room temperature and then it was dried under vacuum for $24 \mathrm{~h}$ at $40^{\circ} \mathrm{C}$ before use. Then, for photografting, $0.8 \mathrm{~mL}$ of VTri, $10 \mathrm{~mL}$ of distilled water, and $3 \mathrm{~mL}$ of acetone were mixed in a Quartz tube and nitrogen was bubbled through the solution for about $30 \mathrm{~min}$ to remove the oxygen before the irradiation. The photoinitiator coated PVDF film was reserved standing in a Quartz tube containing the vinyltriazole solution and the Quartz tube was placed into the photoreactor equipped with a $400 \mathrm{~W}$ medium pressure mercury lamp $(254 \mathrm{~nm})$ to induce grafting. The temperature inside the UV reactor was kept at $60^{\circ} \mathrm{C}$ for $2 \mathrm{~h}[3,9]$. The grafted film was separated and washed with distilled water for several hours to remove the unreacted monomer and PVTri homopolymer. The obtained membrane was then dried in a vacuum oven at $40^{\circ} \mathrm{C}$.

\subsection{Doping of PVDF-g-PVTri Graft Copolymer Membranes} with Triflic Acid (TA). A stoichiometric amount of PVDF- $g$ PVTri films was admixed with TA in DMF, and homogeneous solutions of PVDF- $g$-PVTri-(TA) $)_{x}$ were produced. Solutions with $(x=1.0,2.0$ and 3.0) moles were prepared, where $x$ is the number of moles of $-\mathrm{SO}_{3} \mathrm{H}$ per mole of triazole units. The solutions were cast in polished polytetrafluoroethylene (PTFE) plates, and the solvent was evaporated and dried in 
vacuum oven for several days at $50^{\circ} \mathrm{C}$. The films were stored in glove box for characterizations.

2.5. Characterizations. FTIR spectra were recorded using a Bruker Alpha-P in ATR in the range of $4000-400 \mathrm{~cm}^{-1} .{ }^{1} \mathrm{H}-$ NMR spectra were recorded using a $400 \mathrm{MHz}$ Bruker Avance spectrometer. Chemical shifts are reported in ppm relative to TMS as internal standard.

Thermal stabilities of the polymer electrolytes were examined by a Perkin Elmer STA 6000 Thermal Analyzer. The samples $(\sim 10 \mathrm{mg})$ were heated from $30^{\circ} \mathrm{C}$ to $750^{\circ} \mathrm{C}$ under $\mathrm{N}_{2}$ atmosphere at a scanning rate of $10^{\circ} \mathrm{C} / \mathrm{min}$.

Perkin Elmer JADE Differential Scanning Calorimetry (DSC) was used to explore the thermal transitions of the samples. The samples $(\sim 10 \mathrm{mg})$ were filled into aluminum pans and then heated to the desired temperature at a rate of $10^{\circ} \mathrm{C} / \mathrm{min}$ under nitrogen atmosphere. In heat flux instruments, the sample and reference are heated from the same source and the temperature difference was measured. During the measurements, firstly, the samples were heated from $-40^{\circ} \mathrm{C}$ to $200^{\circ} \mathrm{C}$ and then they were cooled from $200^{\circ} \mathrm{C}$ to $0^{\circ} \mathrm{C}$. Then, the second heating was performed from $0^{\circ} \mathrm{C}$ to $250^{\circ} \mathrm{C}$ at a rate of $10^{\circ} \mathrm{C} / \mathrm{min}$ under nitrogen atmosphere and the second heating curves were evaluated.

Cyclic voltammograms were obtained with a potentiostat CHI instrument Model 842B. Voltammograms of all membranes were recorded in a three-electrode CV system, using a polymer electrolyte modified Pt working electrode and a Pt counter electrode. The reference electrode was silver/silver chloride $(\mathrm{Ag} / \mathrm{AgCl})$ calibrated by a ferrocene/ferricinium redox system. Cyclic voltammetry studies were carried out in $0.1 \mathrm{M}$ tetraethylammonium tetrafluoroborate (TEATFB)/acetonitrile.

The bulk composition and the surface morphology of graft copolymers were determined by the energy dispersive $\mathrm{X}$-ray spectrometry (EDS) method using a scanning electron microscopy (SEM) type JEOL-7001 FESEM (Tokyo, Japan) instrument. All of the samples were previously coated with gold for $150 \mathrm{~s}$ in a sputtering device. The carbon, fluor, and nitrogen were measured from six different regions in the samples and the average value is used.

The proton conductivity studies of the samples were performed using a Novocontrol dielectric-impedance analyzer. The samples were sandwiched between platinum blocking electrodes and the conductivities were measured in the frequency range of $1 \mathrm{~Hz}$ to $3 \mathrm{MHz}$ at $10^{\circ} \mathrm{C}$ intervals. The temperature was controlled with a Novocontrol cryosystem, which is applicable between -150 and $250^{\circ} \mathrm{C}$.

\section{Results and Discussions}

PVTri grafted PVDF films were obtained via UV-induced polymerization of VTri in the presence of BP sensitizer. The films coated with BP were irradiated under a high pressure 400-W mercury lamp and presumably free radicals, formed on the surface by abstraction of fluorines or hydrogens with excited benzophenone, and initiated polymerization as illustrated in Figure 1 $[3,9]$. Finally, anhydrous PEMs were successfully prepared upon doping the grafted films with triflic acid at various ratios.

3.1. FTIR Studies. To provide evidences for grafting and TA doping, FTIR analysis was performed on the membrane in comparison with PVTri homopolymer, pristine PVDF and VTri grafted films, and acid-doped proton conducting membranes as shown in the FTIR spectra revealed in Figure 2. Medium strong peaks in the $1430-1650 \mathrm{~cm}^{-1}$ range belong to the triazole rings of the pristine PVTri homopolymer and are due to the ring stretching $(\mathrm{C}-\mathrm{N}$, $\mathrm{C}=\mathrm{N}$ ) vibrations. The broad peak centered at $3430 \mathrm{~cm}^{-1}$ and the peak at $1270 \mathrm{~cm}^{-1}$ are caused by the $\mathrm{O}-\mathrm{H}$ vibration of molecular water interacting with the pristine PVTri [30] and the $\mathrm{N}-\mathrm{N}$ stretching, respectively. The spectrum of PVDF film displayed a number of strong bands in the range of $1000-1370 \mathrm{~cm}^{-1}$ representing $\mathrm{CF}_{2}$ groups, in addition to, a small band between at $3024 \mathrm{~cm}^{-1}$ and $2982 \mathrm{~cm}^{-1}$ representing stretching vibrations of $-\mathrm{CH}_{2}$ groups $[3,9]$. The grafted films showed additional characteristic bands in the $1430-1650 \mathrm{~cm}^{-1}$ range due to ring stretching $(\mathrm{C}-\mathrm{N}, \mathrm{C}=\mathrm{N})$ vibrations $[7,30]$. The bands at $2800-3600 \mathrm{~cm}^{-1}$ were assigned for $\mathrm{N}-\mathrm{H}$ and $\mathrm{C}-\mathrm{H}$ of the grafted vinyltriazole rings, respectively, which may be mostly involved in a network of hydrogen bonding between triazole rings and moisture. These signs confirmed that the VTri monomer was grafted onto PVDF base films. After doping the PVDF- $g$-PVTri graft polymer, triflic acid gives several absorptions between $1000 \mathrm{~cm}^{-1}$ and $1250 \mathrm{~cm}^{-1}$. The strong bands at 1208 and $1269 \mathrm{~cm}^{-1}$ are attributed to $\mathrm{SO}_{2}$, and a strong absorption peak at $1026 \mathrm{~cm}^{-1}$ most probably belongs to $-\mathrm{SO}_{3}{ }^{-}\left[\mathrm{H}^{+}\right]$. The protonation of the triazole rings is confirmed by the apparition of a peak at around $3170 \mathrm{~cm}^{-1}$ and the broad peaks around $3500 \mathrm{~cm}^{-1}[1,6,31,32]$.

3.2. ${ }^{1} H$-NMR Analysis. Figure 3 show the ${ }^{1} \mathrm{H}-\mathrm{NMR}$ spectra of PVDF and PVDF-g-PVTri graft copolymer. For both samples, the strong peaks at 2.51 and $3.40 \mathrm{ppm}$ are due to DMSO and water, respectively. The ${ }^{1} \mathrm{H}$-NMR spectrum revealed two peaks at 2.9 and $2.3 \mathrm{ppm}$ (a), assigned to the head-to-tail (ht) and tail-to-tail (tt) bonding arrangements of vinylidene fluoride units, respectively $[3,9]$. The peaks at around 8.77 and $8.06 \mathrm{ppm}(\mathrm{b}, \mathrm{c})$ that belong to $-\mathrm{CH}$ protons of the triazole ring typically confirm the successful completion of photoinduced grafting in PVDF- $g$-PVTri graft copolymers $[3,7]$. The integration ratio of the protons in the ${ }^{1} \mathrm{H}$-NMR yielded a degree of grafting of $21 \%$ using the following equation:

$$
\begin{aligned}
& \text { Degree of Grafting }(\mathrm{GD})(\%) \\
& =\frac{\mathrm{MW}_{(\text {vinyltriazole })} \times A(\mathrm{~b}, \mathrm{c})}{\mathrm{MW}_{(\mathrm{PVDF})} \times A(\mathrm{a})} \times 100,
\end{aligned}
$$

where MW is molecular weight and $A(\mathrm{a})$ are the integral areas of the characteristic peak (a) of the PVDF main chain (used as reference peak) and $-\mathrm{CH}$ protons of the triazole ring $(b, c)$ of PVTri, respectively. 


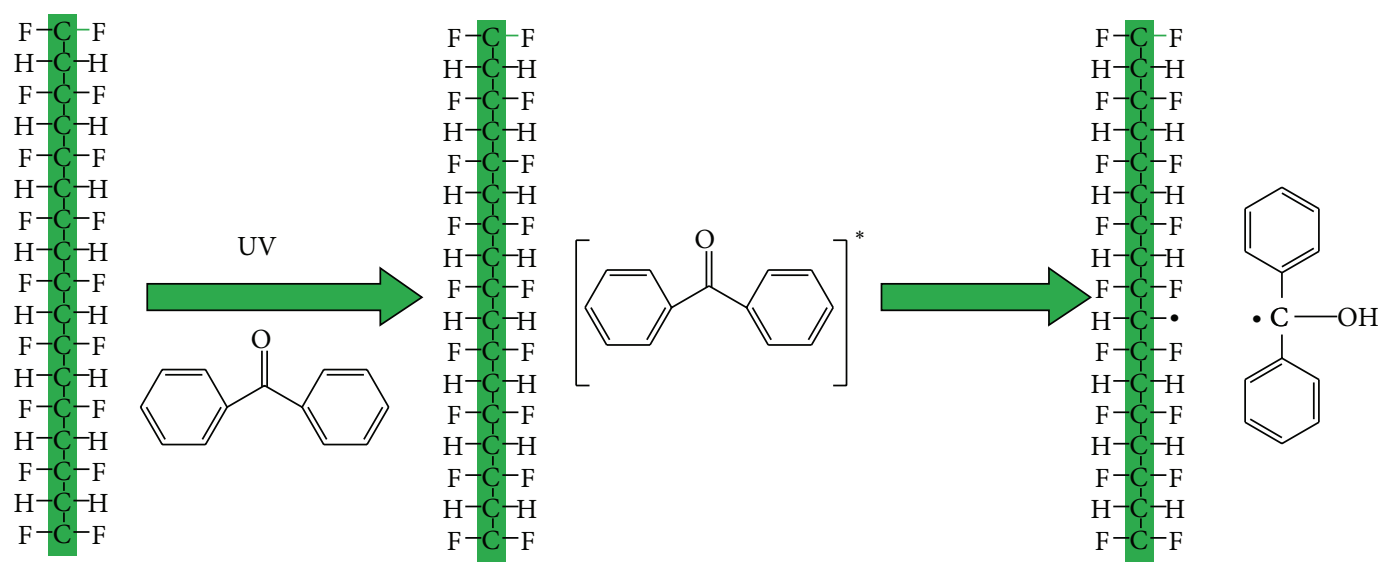

PVDF film
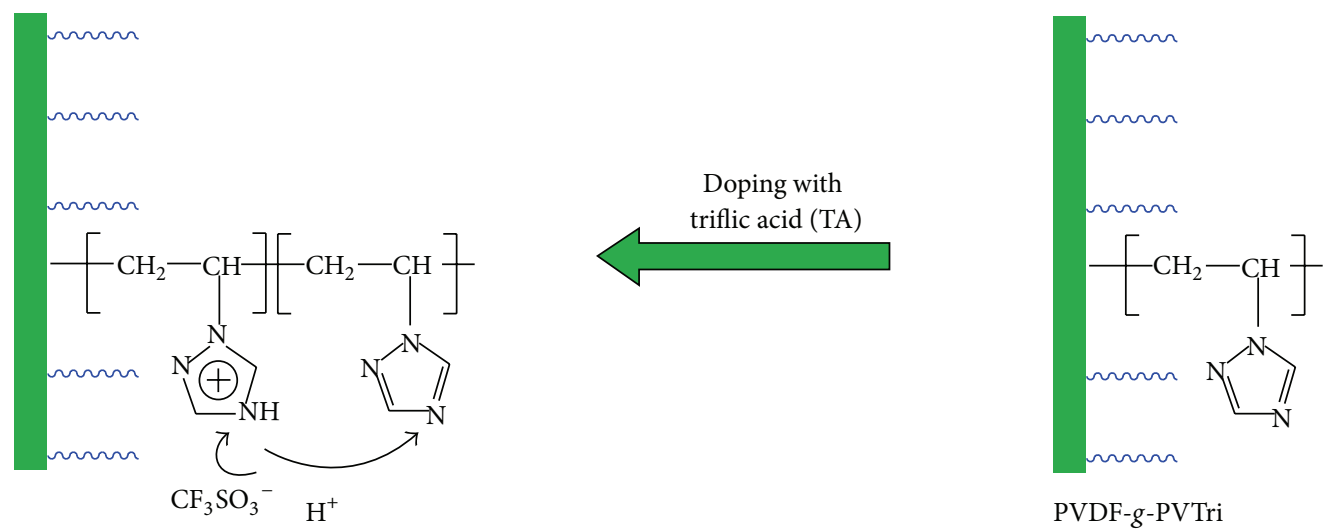

PVDF- $g$-PVTri-(TA) $)_{x}$ membranes

FIgUre 1: Process for the synthesis of PVDF- $g$-PVTri-(TA) $)_{x}$ PEMs by UV surface photografting.

TABLE 1: Azole content of VTri found from EDS results.

\begin{tabular}{lcccc}
\hline Sample & C (\%) & F (\%) & N (\%) & \\
\hline PVDF- $g$-PVTri & 40.76 & 49.85 & 7.29 & Calculated \\
PVDF- $g$-PVTri & 43.71 & 49.62 & 6.47 & Found \\
\hline
\end{tabular}

The composition of PVDF- $g$-PVTri was determined by EDS analysis and the results are summarized in Table 1, which were well supported by $\mathrm{C}, \mathrm{F}$, and $\mathrm{N}$ content calculated in conjunction with grafting degree (GD) obtained from ${ }^{1} \mathrm{H}$ NMR.

3.3. Thermal Analysis. The DSC measurements were carried out under inert atmosphere at a scan rate of $10^{\circ} \mathrm{C} / \mathrm{min}$ and the second heating curves were evaluated. DSC thermograms of the original PVDF, VTri grafted PVDF, TA-doped membranes, and PVTri homopolymer are illustrated in Figure 4. Previously, the Tg of pure PVTri homopolymer and PVDF film were reported as $165^{\circ} \mathrm{C}$ [30] and $-50^{\circ} \mathrm{C}$ [33], respectively. The Tg of PVDF- $g$-PVTri was not observed. The melting point $\left(T_{m}\right)$ of original PVDF was captured at $158^{\circ} \mathrm{C}$ and PVDF- $g$-PVTri exhibits a melting point at approximately $153^{\circ} \mathrm{C}$ (Figure 4). Since the photografting was applied on the membrane form of PVDF, the $T_{m}$ was observed due to the presence of ordered PVDF regions $[3,9]$. Moreover, the reduction in the melting point could be a considerable decrease of the crystalline region of PVDF with the amorphous PVTri grafts. The Tg of TA-doped membranes can not be observed, which may be due to ionic interaction of acidbased units [3] (Table 2).

The thermal stability of the polymers was examined with TGA in comparison with the pristine PVDF and PVTri 


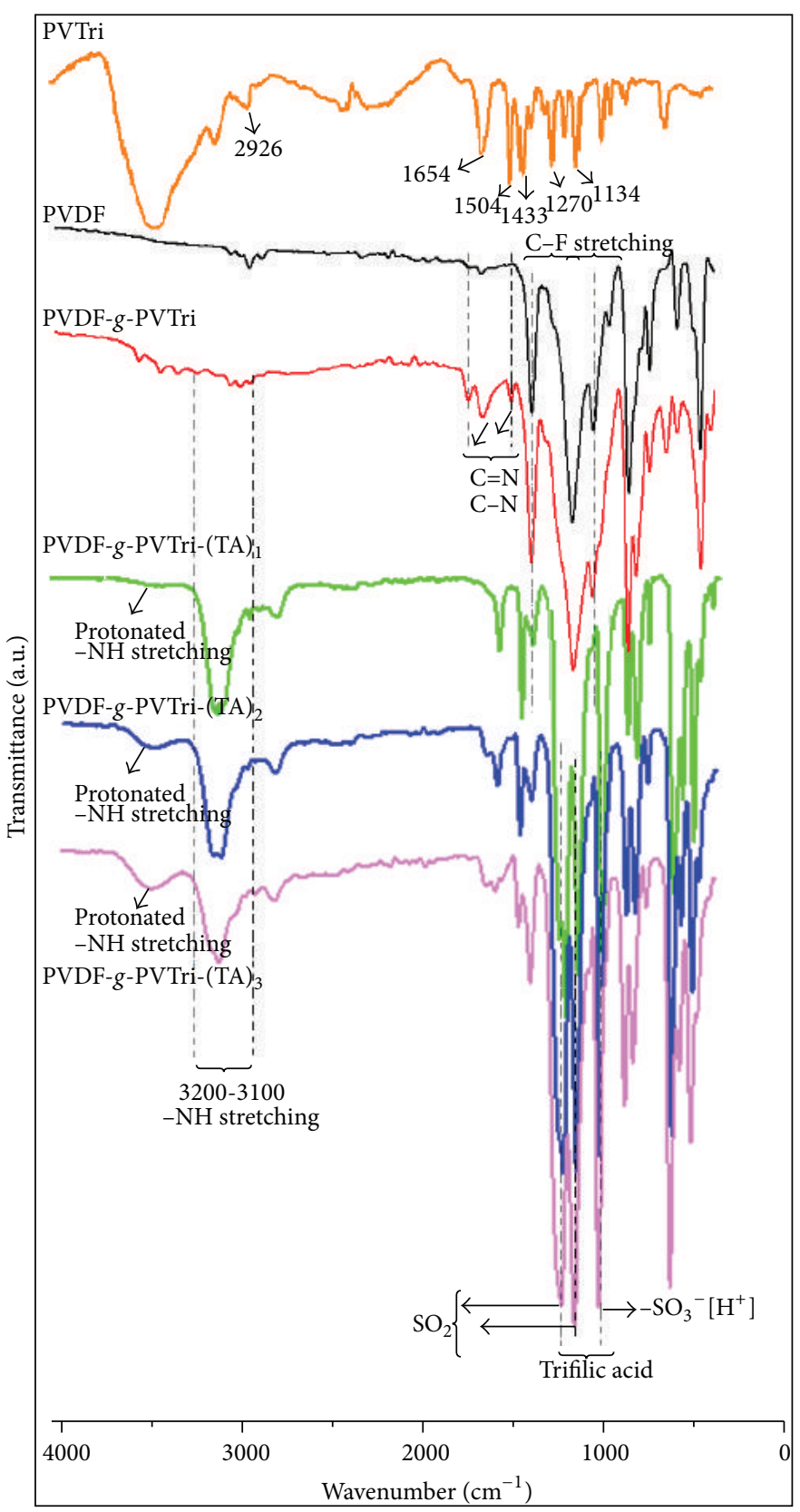

FIgURE 2: FTIR spectra of PVTri, PVDF, PVDF- $g$-PVTri, and acid-doped PVDF- $g$-PVTri-(TA $)_{x}(x=1.0,2.0$ and 3.0$)$ membranes.

homopolymers, PVTri grafted PVDF, TA-doped proton conducting membranes, and the obtained TGA curves shown in Figure 5. For the pristine PVTri homopolymer, the exponential weight decay until $200^{\circ} \mathrm{C}$ can be attributed to absorbed humidity. Above $350^{\circ} \mathrm{C}$, a remarkable weight loss is derived from the thermal decomposition of the side groups and polymer main chain [30]. The original PVDF film showed a single-step degradation pattern with transition at about $450^{\circ} \mathrm{C}$ due to the decomposition of molecular chains of PVDF film $[3,9]$. The PVDF- $g$-PVTri graft copolymer exhibited a two-step degradation pattern at 390 and $460^{\circ} \mathrm{C}$ due to the decomposition of PVTri grafts and the PVDF matrix, respectively. After doping the PVDF-g-PVTri polymer membrane with TA, the thermal stability of the membranes decreases. TA-doped membranes demonstrated a single-step degradation patterns which are thermally stable up to approximately $330^{\circ} \mathrm{C}$. These results are in a good agreement with similar TAdoped membranes obtained by grafting various basic vinylic monomer onto fluorinated polymer films [3]. From the TGA results, it can be suggested that the obtained membranes can be used for testing in high temperature PEMFCs up to $300^{\circ} \mathrm{C}$.

3.4. Morphology. Surface morphologies of the membranes were systematically examined using SEM analysis and the images of pristine PVDF, both undoped and TA-doped PVTri grafted PVDF membranes illustrated in Figure 6. There 


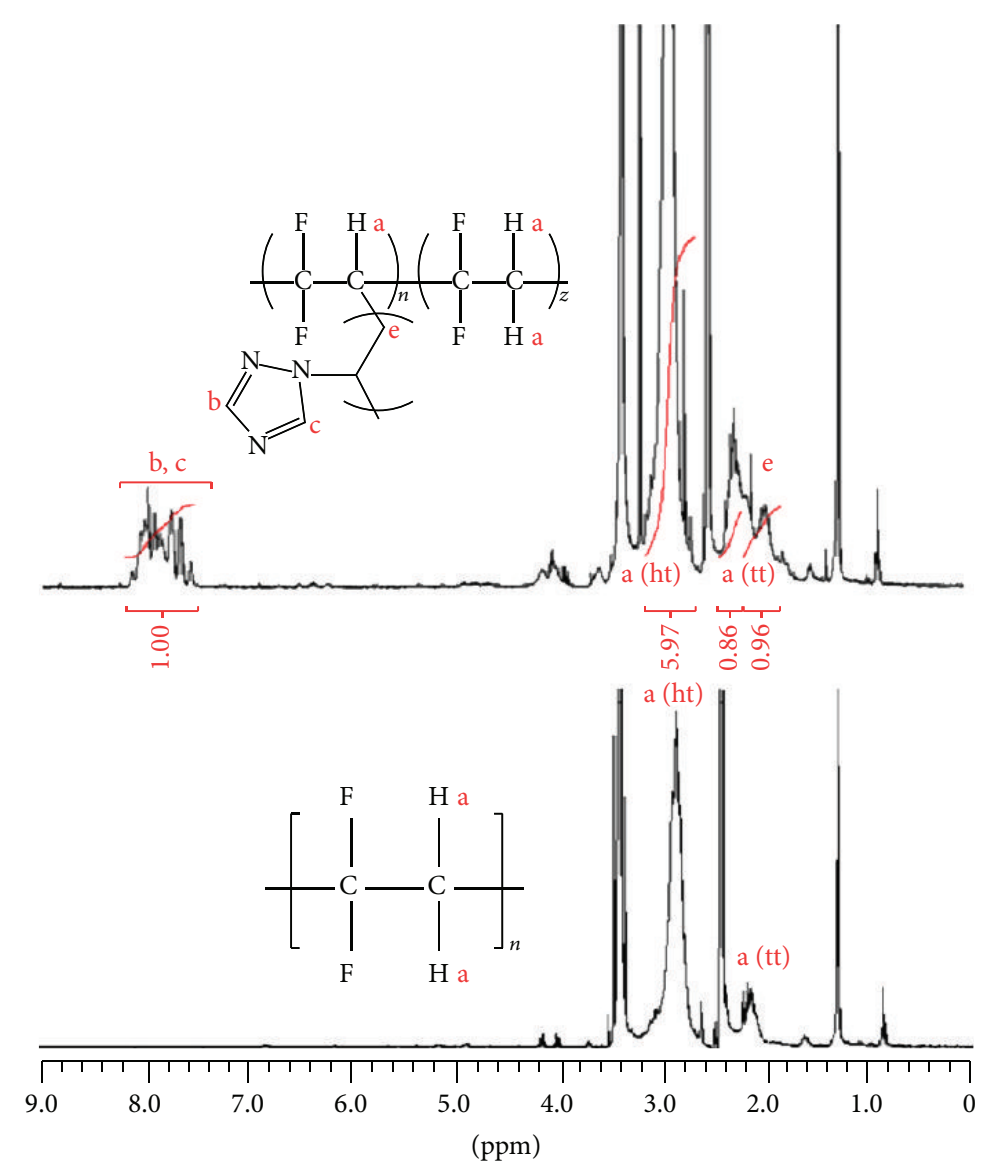

Figure 3: ${ }^{1} \mathrm{H}-\mathrm{NMR}$ spectra of PVDF and PVDF- $g$-PVTri recorded in DMSO- $\mathrm{d}_{6}$.

is formation of a smooth surface of the pristine PVDF membrane as depicted in Figure 6(a). In addition, image (c) showed formation of a smooth surface while in image (b), at the nanometer scale, formation of a highly porous surface was observed. This confirmed that VTri monomer was grafted onto the virgin PVDF (Figure 6(b)). The images of both PVDF (a) and acid-doped membrane (c) show some small cracks due to solvent evaporation during the preparation of membranes [3, 29].

3.5. Proton Conductivity. Proton conductivity is one of the most important properties of polymer electrolyte membranes (PEMs) for fuel cells. The AC conductivities, $\sigma_{\mathrm{ac}}(\omega)$, of the polymers were measured at several temperatures using impedance spectroscopy. Frequency-dependent AC conductivities $\left(\sigma_{\mathrm{ac}}(\omega)\right)$ were measured using the following equation:

$$
\sigma^{\prime}(\omega)=\sigma_{\mathrm{ac}}(\omega)=\varepsilon^{\prime \prime}(\omega) \omega \varepsilon_{o},
$$

where $\sigma^{\prime}(\omega)$ is the real part of conductivity, $\omega=2 \pi f$ is the angular frequency, $\varepsilon_{o}$ is the vacuum permittivity $\left(\varepsilon_{o}=\right.$ $\left.8.852 \times 10^{-14} \mathrm{~F} / \mathrm{cm}\right)$, and $\varepsilon^{\prime \prime}$ is the imaginary part of complex dielectric permittivity $\left(\varepsilon^{*}\right)$. The acid-doped membranes were fixed between additional external parallel plate electrodes (between platinum blocking electrodes) to form a sandwich using the simple two-electrode method and impedance was measured by varying the temperature from $20^{\circ} \mathrm{C}$ to $150^{\circ} \mathrm{C}$.

Figure 7 shows the AC conductivity of PVDF- $g$-PVTri$(\mathrm{TA})_{3}$ versus frequency at several temperatures. As expected, the proton conductivity increases as temperature increases. There are several regions in the curves which are typical for proton conducting polymers. At lower frequency regions, the conductivity increases with log frequency and then leveled off which is due to electrode polarizations. The irregularities at the low frequency side correspond to polarization, blocking the electrode-electrolyte interface, and the conductivity increase at low temperature and high frequencies results from the regular dispersion in polymer electrolytes $[3,7$, 9, 10,34]. Maximum proton conductivities of the obtained anhydrous PEMs are listed in Table 2. It can be seen that as the amounts of triflic acid increase, the conductivity values increase as expected since it has a direct contribution in the conduction mechanism. In the anhydrous conditions, the proton conductivity of PVDF- $g$-PVTri-(TA $)_{3}$ was measured as $6 \times 10^{-3} \mathrm{Scm}^{-1}$ at $150^{\circ} \mathrm{C}$.

The DC conductivity $\left(\sigma_{\mathrm{dc}}\right)$ of the samples was derived from the plateaus of $\log \sigma_{\mathrm{ac}}$ versus $\log \mathrm{F}$ by linear fitting of the data. The DC conductivities of the samples were compared in Figure 8 . The conductivity isotherm illustrates that the DC conductivity depends on the temperature and doping ratio 
TABLE 2: Doping ratio with TA and $T_{g}$ and maximum proton conductivity values of PVDF based membranes.

\begin{tabular}{|c|c|c|c|}
\hline Sample name & Doping ratio with TA & $T_{g}\left({ }^{\circ} \mathrm{C}\right)$ & Max. proton conductivity $\left(\mathrm{Scm}^{-1}\right)$ \\
\hline PVDF & - & $-50^{\circ} \mathrm{C}$ & - \\
\hline PVTri & - & $165^{\circ} \mathrm{C}$ & $1.13 \times 10^{-7} \mathrm{Scm}^{-1}$ at $150^{\circ} \mathrm{C}$ \\
\hline PVDF- $g$-PVTri & - & $\mathrm{a}$ & - \\
\hline PVDF- $g$-PVTri-(TA) $)_{1}$ & $1: 1$ & a & $7 \times 10^{-4} \mathrm{Scm}^{-1}$ at $150^{\circ} \mathrm{C}$ \\
\hline PVDF- $g$-PVTri-(TA) $)_{2}$ & $1: 2$ & a & $3 \times 10^{-3} \mathrm{Scm}^{-1}$ at $150^{\circ} \mathrm{C}$ \\
\hline PVDF- $g$-PVTri-(TA) ${ }_{3}$ & $1: 3$ & $\mathrm{a}$ & $6 \times 10^{-3} \mathrm{Scm}^{-1}$ at $150^{\circ} \mathrm{C}$ \\
\hline
\end{tabular}

a: $T_{g}$ was not observed due to ionic interactions that may result in the restriction of the segmental relaxations.

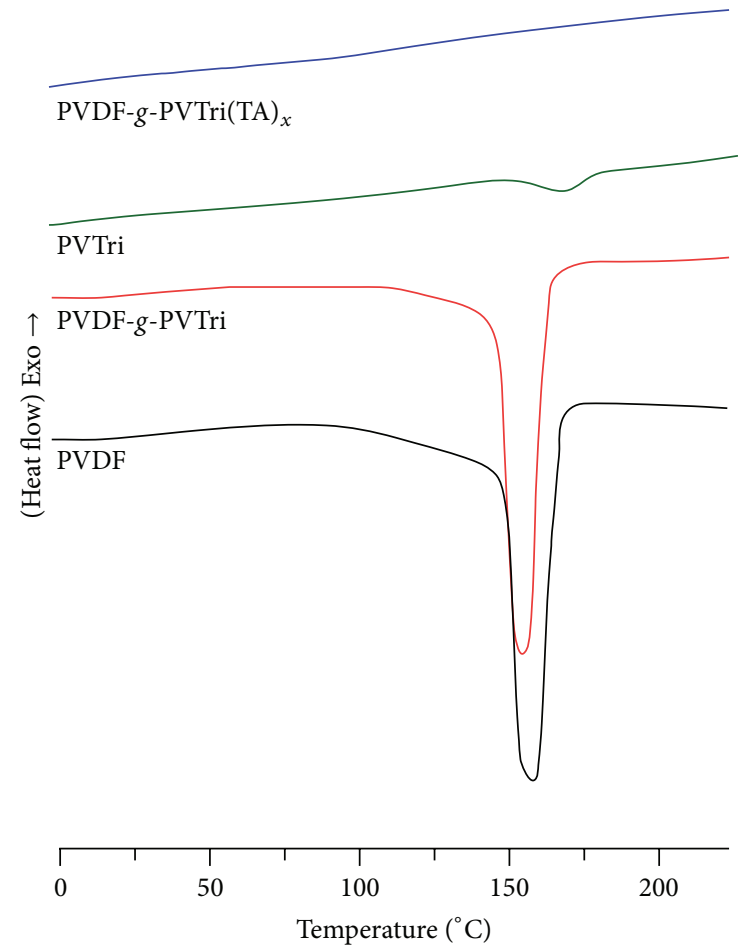

FIGURE 4: DSC thermograms of PVDF, PVTri, PVDF- $g$-PVTri, and PVDF- $g$-PVTri-(TA $)_{x}(x=1.0,2.0$ and 3.0) membranes recorded under $\mathrm{N}_{2}$ atmosphere at a heating rate of $10^{\circ} \mathrm{C} / \mathrm{min}$.

of triflic acid. The DC curves are closer to linear-type curves which can be explained with the following equation:

$$
\ln \sigma=\ln \sigma_{0}-\frac{E_{a}}{k T},
$$

where $\sigma_{0}$ is the preexponential terms, $E_{a}$ is the activation energy, and $k$ is the Boltzmann constant. Arrhenius behavior is generally observed in the matrices where, during the measurement temperature range, no $T_{g}$ was observed and there is no change in linearity of DC curve.

Recently, many researchers have tried to get very different methods such as irradiation [2], photografting [3], UV-light [9], or ATRP methods [11, 35-41] to prepare PEMs that are composed of PVDF since it is cheaper than Nafion while analogous in chemical nature to Nafion. The proton conductivity in these studies is based on the humidity content and not applicable at high temperatures. The grafted structure

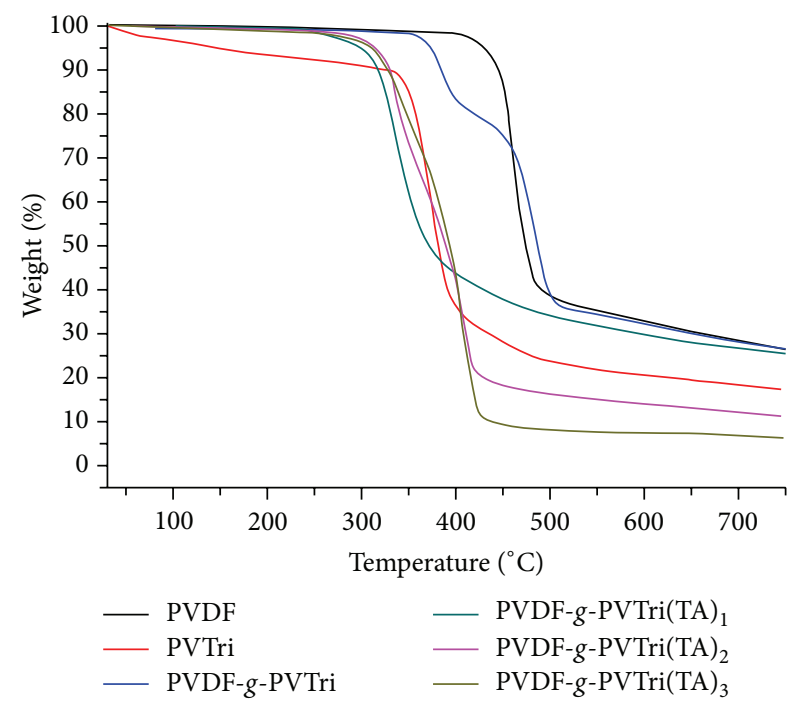

Figure 5: TG thermograms of PVDF, PVTri, PVDF- $g$-PVTri, and PVDF- $g$-PVTri-(TA $)_{x}(x=1.0,2.0$ and 3.0) membranes at a heating rate of $10^{\circ} \mathrm{C} / \mathrm{min}$ in inert atmosphere.

acid-doped PVTri was previously studied and high proton conductivity was reported as $0.005 \mathrm{~S} / \mathrm{cm}$ at $150^{\circ} \mathrm{C}$ [30]. So far, very few studies of PVDF and azole based anhydrous PEMs designs were reported $[3,9,29]$. In these studies, a novel UVinduced polymerization method was employed in the grafting of styrene and 4-(chloromethyl)styrene onto partially fluorinated PVDF [3, 9]. Golcuk et al., reported the preparation of TA-doped triazole-functional poly(chloromethyl styrene) grafted PVDF, PVDF- $g$-PCMS-Tri-1TA, with a maximum proton conductivity of $0.02 \mathrm{~S} / \mathrm{cm}$ at $150^{\circ} \mathrm{C}$ and anhydrous conditions [3]. In another work reported by Golcuk et al., a maximum proton conductivity of $5 \times 10^{-5} \mathrm{~S} / \mathrm{cm}$ at $150^{\circ} \mathrm{C}$ was found for triazole doped poly(styrenesulfonic acid) grafted PVDF. Besides, Lepit et al. reported a maximum proton conductivity of $1 \times 10^{-3} \mathrm{~S} / \mathrm{cm}$ at $100^{\circ} \mathrm{C}$ for 1-vinylimidazole (VIm) and PVDF based PEMs prepared via radiationinduced grafting [29].

In the present study, PVDF provided good film formability and high thermal and mechanically stable matrix in the obtained graft copolymer membranes (PVDF- $g$-PVTri). The proton conductivity is carried out between triazole and triflic acid units in the grafted matrices. The highest maximum proton conductivity of PVDF-g-PVTri-(TA) ${ }_{3}$ was found as 


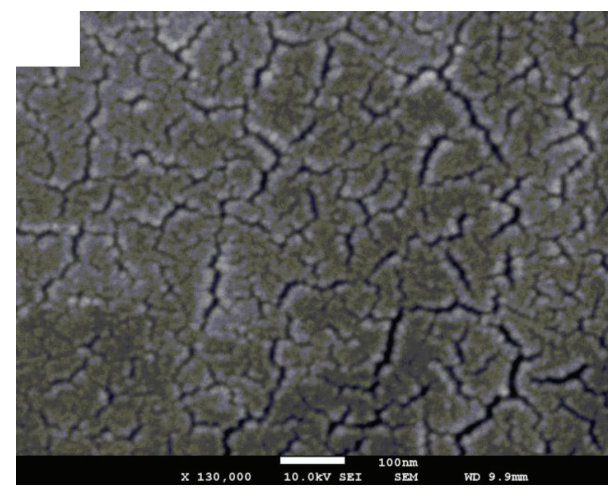

(a)

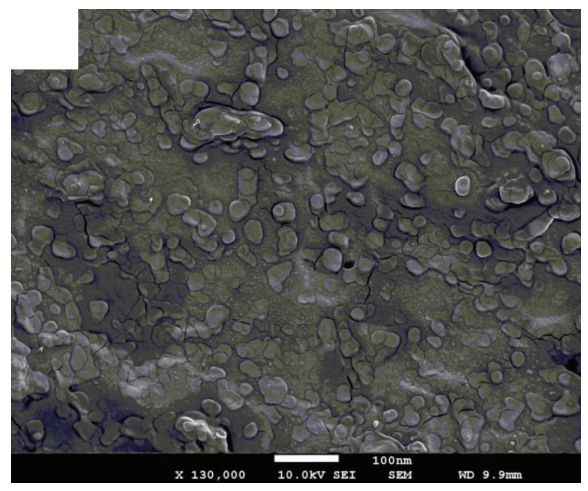

(b)

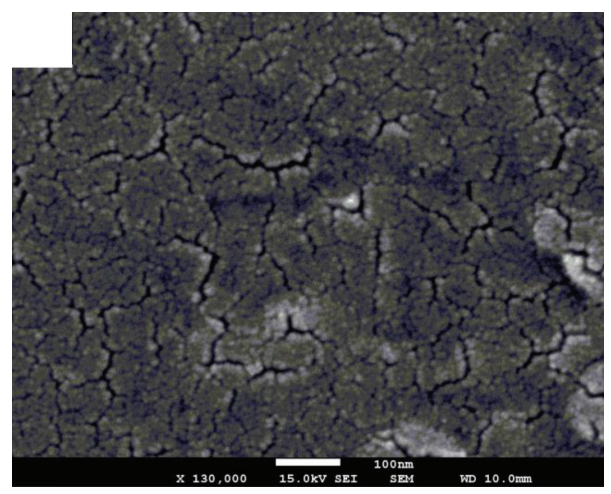

(c)

Figure 6: SEM images of the surface of (a) virgin PVDF, (b) PVDF- $g$-PVTri, and (c) PVDF- $g$-PVTri-(TA) ${ }_{3}$ membranes at $100 \mathrm{~nm}$ scale level by 130,000x magnification, respectively.

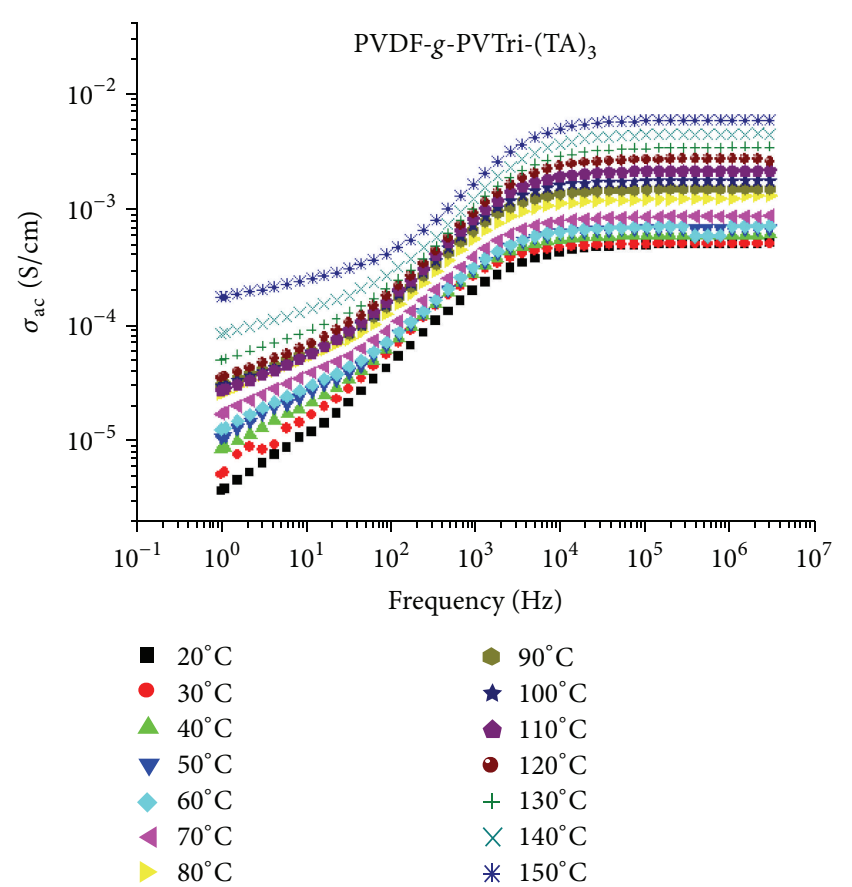

FIGURE 7: AC conductivity versus frequency of PVDF- $g$-PVTri$(\mathrm{TA})_{3}$ at several temperatures.
$6 \times 10^{-3} \mathrm{~S} / \mathrm{cm}$ at $150^{\circ} \mathrm{C}$. Since the proton conductivity is directly proportional to the amount of triflic acid in the membrane, the conductivity values of acid-doped PVDF-g-PVTri increase as expected. Furthermore, the porous morphology of PVDF- $g$-PVTri graft copolymers participates in good proton conduction because of strong interaction between $-\mathrm{SO}_{3} \mathrm{H}$ groups of triflic acid and the triazole units of PVTri [34]. This continuous pathway may transmit proton transfer over the sulfonic acid groups and triazole groups $[3,6,10]$.

3.6. Cyclic Voltammetry. Cyclic voltammogram of PVDF$g$-PVTri-(TA $)_{3}$ was given in Figure 9. In fact, by using a platinum work electrode, a platinum auxiliary electrode, and an $\mathrm{Ag} / \mathrm{Ag}^{+}$reference electrode, the measurement was done in a typical three-electrode cell that included $0.1 \mathrm{~mol} \mathrm{dm}^{-3}$ $\mathrm{CH}_{3} \mathrm{CN}$ solution of tetrabutylammonium hexafluorophosphate (TBAPF6). By showing that the PVDF-g-PVTri-(TA) reveals no peak within in the anodic and cathodic sweep $(-2.0$ to $2.0 \mathrm{~V}$ potential range), the voltammogram indicates that the electrochemical stability window is about $4 \mathrm{~V}$. Therefore, it can be said that the PVDF-g-PVTri-(TA) 3 membrane had an adequate electrochemical stability under fuel cell conditions. 


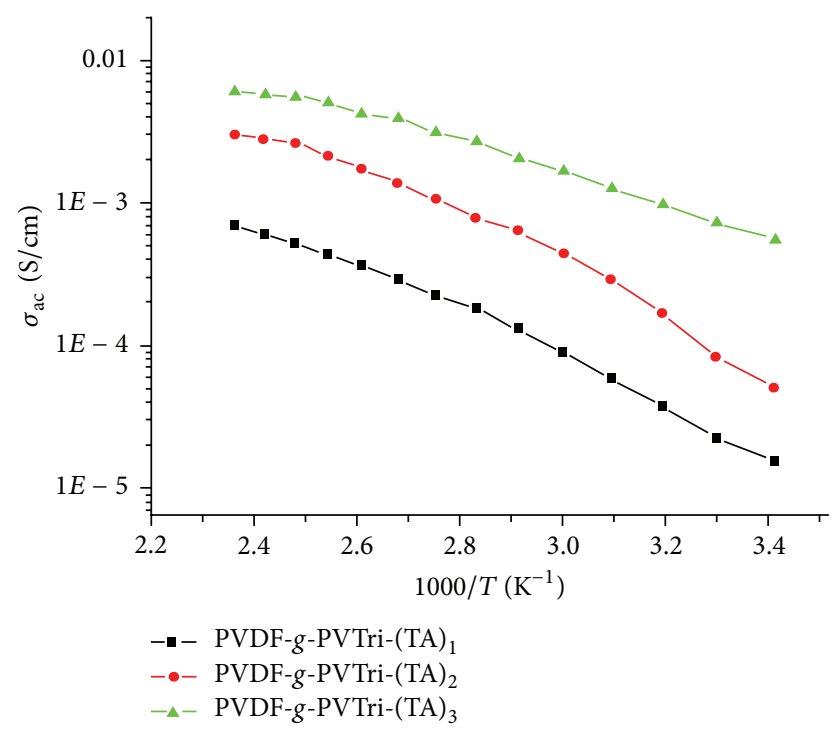

FIGURE 8: Variation of the DC proton conductivity of PVDF- $g$ PVTri-(TA $)_{x}(x=1.0,2.0$ and 3.0) membranes as a function of reciprocal temperature.

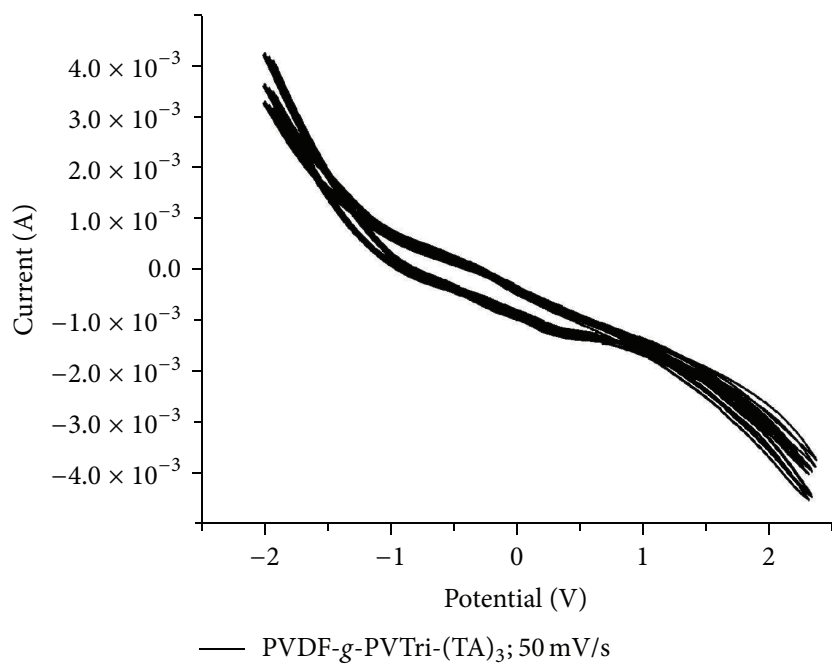

FIGURE 9: Cyclic voltammograms of PVDF- $g$-PVTri-(TA) ${ }_{3}$ in $0.1 \mathrm{M}$ TBATFB/acetonitrile. Curves were obtained with a scan rate of $50 \mathrm{mV} / \mathrm{s}$.

\section{Conclusions}

Proton exchange membranes (PEMs) were prepared by UV photoinduced surface grafting of 1-vinyl-1,2,4-triazole (VTri) monomer onto poly(vinylidene fluoride) (PVDF) followed by doping with triflic acid to achieve PVDF- $g$-PVTri-(TA) $)_{x}$ $(x=1.0,2.0$ and 3.0) membranes where $x$ is the number of moles of TA per mole of VTri. The success of grafting was evidenced using ${ }^{1} \mathrm{H}-\mathrm{NMR}$ and FTIR. Thermal properties were examined by TGA and DSC measurements. TGA showed that the PVDF- $g$-PVTri and PVDF- $g$-PVTri-(TA) membranes were thermally stable up to $390^{\circ} \mathrm{C}$ and $330^{\circ} \mathrm{C}$, respectively. NMR showed a grafting efficiency of $21 \%$, which was, as well, supported by EDS analysis. CV study illustrated that electrochemical stability domain for PVDF- $g$-PVTri$(\mathrm{TA})_{3}$ extended over $4.0 \mathrm{~V}$. The proton conductivity of the membranes was measured and PVDF- $g$-PVTri-(TA) $)_{3}$, with a degree of grafting of $21 \%$, showed a maximum proton conductivity of approximately $6 \times 10^{-3} \mathrm{Scm}^{-1}$ at $150^{\circ} \mathrm{C}$ under anhydrous conditions. Therefore, this thermomechanically stable conducting graft copolymer membrane may be a suitable candidate to be employed in high temperature fuel cells.

\section{Conflict of Interests}

The authors declare that there is no conflict of interests regarding the publication of this paper.

\section{Acknowledgments}

The authors would like to convey their thanks to Fatih University, Bio-NanoTechnology R\&D Center, for providing laboratory facilitates to measure SEM and EDS measurements. This work was supported by the Scientific Research Fund of Fatih University under the Project no. P50021201_B.

\section{References}

[1] D. Sinirlioglu, S. U. Celik, A. E. Muftuoglu, and A. Bozkurt, "Novel membranes based on poly(5-(methacrylamido)tetrazole) and sulfonated polysulfone for proton exchange membrane fuel cells," Journal of Applied Polymer Science, vol. 131, no. 7, pp. 3633-3642, 2014.

[2] E. E. Abdel-Hady, M. M. El-Toony, and M. O. Abdel-Hamed, "Grafting of glycidyl methacrylate/styrene onto polyvinyldine fluoride membranes for proton exchange fuel cell," Electrochimica Acta, vol. 103, pp. 32-37, 2013.

[3] S. Golcuk, A. E. Muftuoglu, S. U. Celik, and A. Bozkurt, "Synthesis and characterization of polymer electrolyte membranes based on PVDF and styrene via photoinduced grafting," Journal of Polymer Research, vol. 20, no. 5, article 144, 2013.

[4] D. Sinirlioglu, S. U. Celik, A. E. Muftuoglu, and A. Bozkurt, "Proton conducting copolymer electrolytes based on vinyl phosphonic acid and 5-(methacrylamido)tetrazole," Macromolecular Chemistry and Physics, vol. 215, no. 3, pp. 269-279, 2014.

[5] P. Danwanichakul and P. Sirikhajornnam, "An investigation of chitosan-grafted-poly(vinyl alcohol) as an electrolyte membrane," Journal of Chemistry, vol. 2013, Article ID 642871, 9 pages, 2013.

[6] D. Sinirlioglu, A. Aslan, A. E. Muftuoglu, and A. Bozkurt, "Synthesis and proton conductivity studies of methacrylate and methacrylamide based azole functional novel polymer electrolytes," Journal of Applied Polymer Science, vol. 131, no. 4, pp. 1984-1991, 2014.

[7] D. Sinirlioglu, A. E. Muftuoglu, and A. Bozkurt, "5-(methacrylamido)tetrazole and vinyl triazole based copolymers as novel anhydrous proton conducting membranes," Journal of Polymer Research, vol. 20, no. 9, article 242, pp. 1-10, 2013. 
[8] S. Ü. Çelik and A. Bozkurt, "Novel boron-containing triazole functional copolymers as anhydrous proton conductive membranes," Journal of Polymer Research, vol. 20, no. 1, article 63, 2012.

[9] S. Golcuk, A. E. Muftuoglu, S. U. Celik, and A. Bozkurt, "Synthesis and characterization of polymer electrolyte membranes based on PVDF and styrene via photoinduced grafting," Journal of Polymer Research, vol. 20, no. 5, article 144, 2013.

[10] S. Ü. Çelik, A. Bozkurt, and S. S. Hosseini, "Alternatives toward proton conductive anhydrous membranes for fuel cells: heterocyclic protogenic solvents comprising polymer electrolytes," Progress in Polymer Science, vol. 37, no. 9, pp. 1265-1291, 2012.

[11] L. Sauguet, B. Boyer, B. Ameduri, and B. Boutevin, "Synthesis and characterization of poly(vinylidene fluoride)-gpoly(styrene) graft polymers obtained by atom transfer radical polymerization of styrene," Macromolecules, vol. 39, no. 26, pp. 9087-9101, 2006.

[12] J. Chen, M. Asano, T. Yamaki, and M. Yoshida, "Preparation and characterization of chemically stable polymer electrolyte membranes by radiation-induced graft copolymerization of four monomers into ETFE films," Journal of Membrane Science, vol. 269, no. 1-2, pp. 194-204, 2006.

[13] M. Asano, J. Chen, Y. Maekawa, T. Sakamura, H. Kubota, and M. Yoshida, "Novel UV-induced photografting process for preparing poly(tetrafluoroethylene)-based proton-conducting membranes," Journal of Polymer Science A: Polymer Chemistry, vol. 45, no. 13, pp. 2624-2637, 2007.

[14] J. Chen, M. Asano, Y. Maekawa, and M. Yoshida, "Suitability of some fluoropolymers used as base films for preparation of polymer electrolyte fuel cell membranes," Journal of Membrane Science, vol. 277, no. 1-2, pp. 249-257, 2006.

[15] J. Chen, M. Asano, T. Yamaki, and M. Yoshida, "Chemical and radiation crosslinked polymer electrolyte membranes prepared from radiation-grafted ETFE films for DMFC applications," Journal of Power Sources, vol. 158, no. 1, pp. 69-77, 2006.

[16] J. Chen, M. Asano, Y. Maekawa, T. Sakamura, H. Kubota, and M. Yoshida, "Preparation of fuel cell membranes by photografting in vapor and liquid phases," Electrochemical and Solid-State Letters, vol. 9, no. 5, pp. G184-G186, 2006.

[17] S. Hasegawa, Y. Suzuki, and Y. Maekawa, "Preparation of poly(ether ether ketone)-based polymer electrolytes for fuel cell membranes using grafting technique," Radiation Physics and Chemistry, vol. 77, no. 5, pp. 617-621, 2008.

[18] J. Qiu, J. Zhang, J. Chen et al., "Amphoteric ion exchange membrane synthesized by radiation-induced graft copolymerization of styrene and dimethylaminoethyl methacrylate into PVDF film for vanadium redox flow battery applications," Journal of Membrane Science, vol. 334, no. 1-2, pp. 9-15, 2009.

[19] U. Septiani, J. Chen, M. Asano, Y. Maekawa, M. Yoshida, and H. Kubota, "Influence of pre-irradiation atmosphere on the properties of polymer electrolyte membranes prepared using radiation grafting method," Journal of Materials Science, vol. 42, no. 4, pp. 1330-1335, 2007.

[20] G. Fei, M.-L. Hwang, J.-Y. Sohn, Y. C. Nho, and J. Shin, "Radiolytic preparation of PFA-g-PVBSA membranes as a polymer electrolyte membrane," Nuclear Instruments and Methods in Physics Research B: Beam Interactions with Materials and Atoms, vol. 274, pp. 83-86, 2012.

[21] M. Hwang, J. Song, B. Ko, J. Sohn, Y. Nho, and J. Shin, "Radiation-induced grafting of vinylbenzyl chloride onto a poly(ether ether ketone) film," Nuclear Instruments and Methods in Physics Research B, vol. 281, pp. 45-50, 2012.
[22] J. Shin, G. Fei, S. Kang, B. Ko, Y. Lee, and Y. Chang Nho, "Influence of the radiation grafting conditions on the cross-sectional distribution of poly(vinylbenzyl chloride) grafted polymer onto poly(tetrafluoroethylene-co-hexafluoropropylene) films," Journal of Applied Polymer Science, vol. 117, no. 4, pp. 2380-2385, 2010.

[23] C. Schmidt and G. Schmidt-Naake, "Proton conducting membranes obtained by doping radiation-grafted basic membrane matrices with phosphoric acid," Macromolecular Materials and Engineering, vol. 292, no. 10-11, pp. 1164-1175, 2007.

[24] M. M. Nasef, A. A. Ali, and H. Saidi, "Composite proton conducting membrane by radiation-induced grafting of 1vinylimidazole onto poly(ethylene-co-tetrafluoroethylene) and phosphoric acid doping," High Performance Polymers, vol. 25, no. 2, pp. 198-204, 2013.

[25] M. M. Nasef, E. Shamsaei, H. Saidi, A. Ahmad, and K. Z. M. Dahlan, "Preparation and characterization of phosphoric acid composite membrane by radiation induced grafting of 4vinylpyridine onto poly(ethylene-co- tetrafluoroethylene) followed by phosphoric acid doping," Journal of Applied Polymer Science, vol. 128, no. 1, pp. 549-557, 2013.

[26] S. Hasegawa, S. Takahashi, H. Iwase et al., "Radiation-induced graft polymerization of functional monomer into poly(ether ether ketone) film and structure-property analysis of the grafted membrane," Polymer, vol. 52, no. 1, pp. 98-106, 2011.

[27] J. Chen, M. Asano, T. Yamaki, and M. Yoshida, "Preparation of sulfonated crosslinked PTFE-graft-poly(alkyl vinyl ether) membranes for polymer electrolyte membrane fuel cells by radiation processing," Journal of Membrane Science, vol. 256, no. 1-2, pp. 38-45, 2005.

[28] B. Fayolle, L. Audouin, and J. Verdu, "Radiation induced embrittlement of PTFE," Polymer, vol. 44, no. 9, pp. 2773-2780, 2003.

[29] A. Lepit, N. A. Aini, N. K. Jaafar et al., "Influences of co-polymerization 1-vinylimidazole onto $\gamma$-irradiated poly(vinylidene flouride) membranes," International Journal of Electrochemical Science, vol. 7, no. 9, pp. 8560-8577, 2012.

[30] S. Ü. Çelik, A. Aslan, and A. Bozkurt, "Phosphoric acid-doped poly(1-vinyl-1,2,4-triazole) as water-free proton conducting polymer electrolytes," Solid State Ionics, vol. 179, no. 19-20, pp. 683-688, 2008.

[31] Ş. Özden, S. Ü. Çelik, and A. Bozkurt, "Synthesis and proton conductivity studies of polystyrene-based triazole functional polymer membranes," Journal of Polymer Science A: Polymer Chemistry, vol. 48, no. 22, pp. 4974-4980, 2010.

[32] A. Bozkurt, "Anhydrous proton conductive polystyrene sulfonic acid membranes," Turkish Journal of Chemistry, vol. 29, no. 2, pp. 117-123, 2005.

[33] W. Tang, T. Zhu, P. Zhou et al., "Poly(vinylidene fluoride)/ poly(methyl methacrylate) $/ \mathrm{TiO}_{2}$ blown films: preparation and surface study," Journal of Materials Science, vol. 46, no. 20, pp. 6656-6663, 2011.

[34] M. Hazarika and T. Jana, "Proton exchange membrane developed from novel blends of polybenzimidazole and poly(vinyl1,2,4-triazole)," ACS Applied Materials \& Interfaces, vol. 4, no. 10, pp. 5256-5265, 2012.

[35] Y. W. Kim, J. K. Choi, J. T. Park, and J. H. Kim, "Proton conducting poly(vinylidene fluoride-co-chlorotrifluoroethylene) graft copolymer electrolyte membranes," Journal of Membrane Science, vol. 313, no. 1-2, pp. 315-322, 2008. 
[36] W. Wang and L. Chen, “'Smart' membrane materials: preparation and characterization of PVDF- $g$-PNIPAAm graft copolymer," Journal of Applied Polymer Science, vol. 104, no. 3, pp. 1482-1486, 2007.

[37] Y. W. Kim, D. K. Lee, K. J. Lee, and J. H. Kim, "Single-step synthesis of proton conducting poly(vinylidene fluoride) (PVDF) graft copolymer electrolytes," European Polymer Journal, vol. 44, no. 3, pp. 932-939, 2008.

[38] N. A. Hashim, F. Liu, and K. Li, "A simplified method for preparation of hydrophilic PVDF membranes from an amphiphilic graft copolymer," Journal of Membrane Science, vol. 345, no. 1-2, pp. 134-141, 2009.

[39] Y. W. Chen, D. M. Liu, Q. L. Deng, X. H. He, and X. F. Wang, "Atom transfer radical polymerization directly from poly(vinylidene fluoride): surface and antifouling properties," Journal of Polymer Science A: Polymer Chemistry, vol. 44, no. 11, pp. 3434-3443, 2006.

[40] Z. Ke, B. Dai, L. Li, G. Yan, and D. Zhou, "Thermoresponsive surface prepared by atom transfer radical polymerization directly from poly(vinylidene fluoride) for control of cell adhesion and detachment," Journal of Applied Polymer Science, vol. 115, no. 2, pp. 976-980, 2010.

[41] Y. L. Liu, C. C. Han, T. C. Wei, and Y. Chang, "Surfaceinitiated atom transfer radical polymerization from porous poly(tetrafluoroethylene) membranes using the C-F groups as initiators," Journal of Polymer Science A: Polymer Chemistry, vol. 48, no. 10, pp. 2076-2083, 2010. 

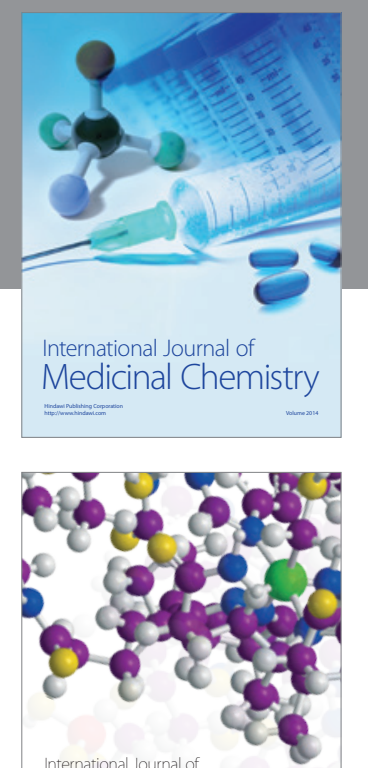

\section{Carbohydrate} Chemistry

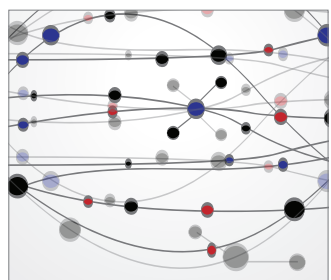

The Scientific World Journal
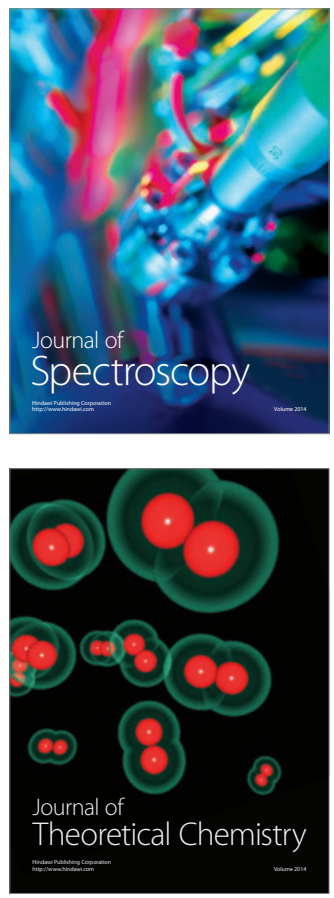
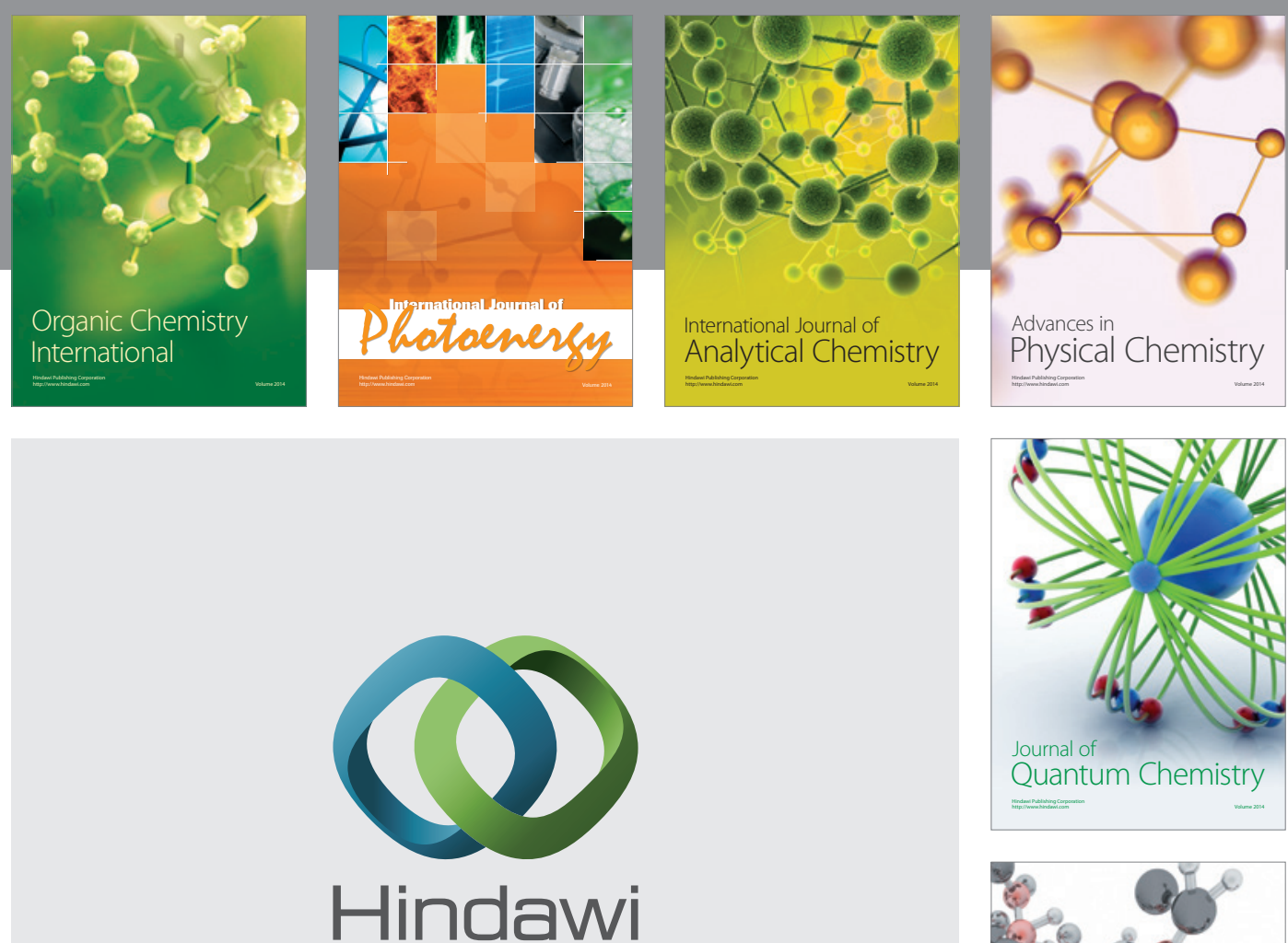

Submit your manuscripts at

http://www.hindawi.com

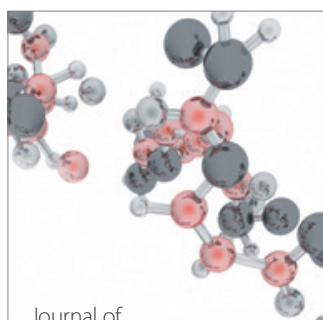

Analytical Methods

in Chemistry

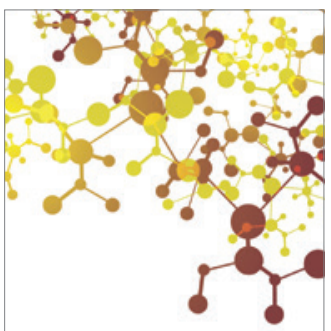

Journal of

Applied Chemistry

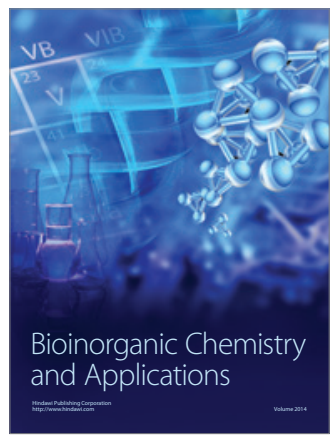

Inorganic Chemistry
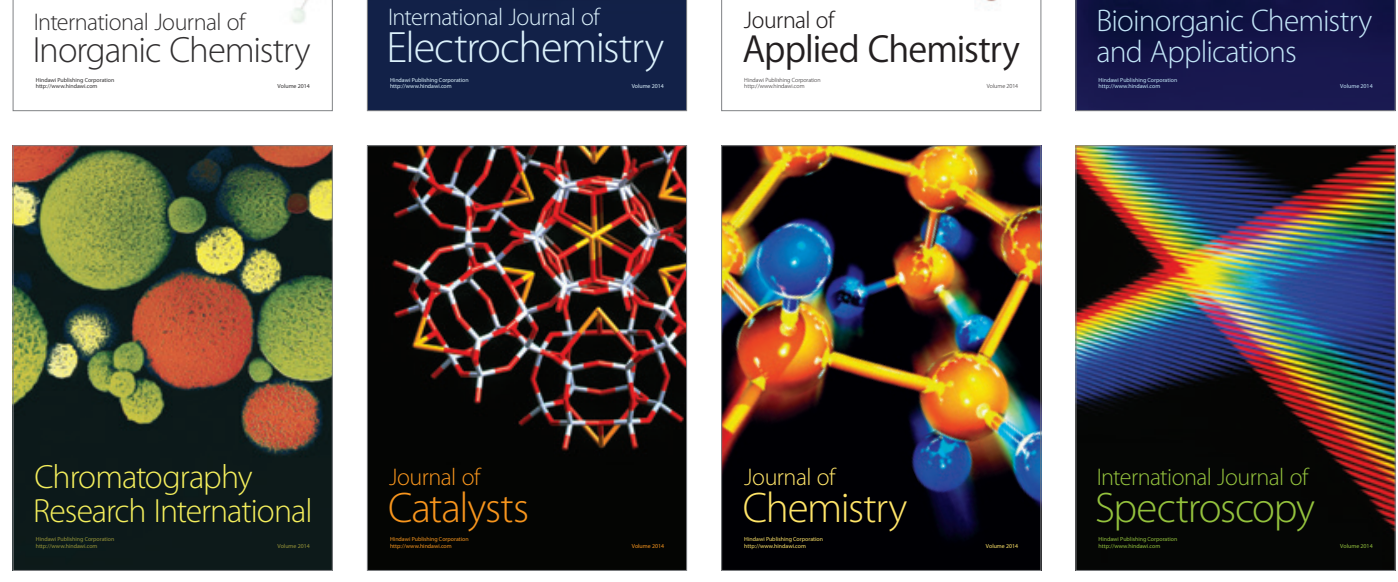